\title{
USO DE SPHAGNUM RECURVUM P. BEAUV. COMO BIOFILTRO NO MONITO- RAMENTO DE POLUIÇÃO AÉREA INDUSTRIAL DE METAIS PESADOS
}

\section{Jutta Gutberlet}

\begin{abstract}
RESUMO - O uso de bioindicadores e biofiltros, principalmente plantas inferiores, representa uma alternativa eficiente no monitoramento da qualidade ambiental. A vantagem do emprego de vegetais na avaliação da contaminação ambiental consiste no reduzido custo de instalação e no fato de poder retratar uma situação global, integrando a soma dos diferentes efeitos dos agentes contaminantes. Segundo o método "moss-bag", adaptado aos fatores regionais específicos, foram empregados saquinhos de nylon contendo o musgo Sphagnum recurvum P. Beauv. como biofiltro dentro do estudo realizado na Serra do Mar de Cubatão/SP/Brasil. A contaminação atmosférica de metais pesados ( $\mathrm{Al}, \mathrm{Fe}, \mathrm{Ni}, \mathrm{Zn}$ ) foi monitorada mensalmente durante o-ano de 1987. Primeiros dados analíticos sobre a acumulação absoluta e relativa dos metais pesados em ppm e porcentagem $(\%)$, respectivamente, confirmam a excelente capacidade de retenção de agentes contaminantes atmosféricos pelo musgo.

Palavras-chave: Biomonitoramente, Metais pesados, "moss-bag", Poluição aérea, Serra do Mar/Cubatão.
\end{abstract}

\begin{abstract}
Bioindcators and biofilters, especially lower plants, represent an efficient alternative for the monitoring of environmental quality. The advantage by using plants for recognition and evaluation of certain air pollutants consists in the relatively low cost installation and the revealing of the global situation of air pollution in a determined area, by adding up all the effects of the different pollutants. Moss bags containing Sphagnum recurvum P. Beauv. were introduced as biofilters, according to the established moss-bag-method, for the heavy metalmonitoring realized during 1987 at the study area Serra do Mar/Cubatão, Brazil. First analytical results on the absolute and relative accumulation of some heavy metals $(\mathrm{Al}, \mathrm{Fe}, \mathrm{Ni}, \mathrm{Zn}$ ) are presented in ppm and percentage (\%). The results confirm the excellent capacity os moss beeing used for surveying atmosferic pollutants.
\end{abstract}

Key words: Air pollution, Biomonitoring, Heavy metals, Moss-bag, Serra do Mar/Cubatão.

\section{Introdução}

Bioindicadores são organismos (principalmente vegetais) que, devido à sua sensibilidade específica aos poluentes, apresentam alterações desde metabólicas até ecológicas, integrando os efeitos dos agentes contaminantes, como por ex:

- alterações em processos fisiológicos

- mudanças anatômicas e morfológicas

resultando em:

- necroses e cloroses

- redução no crescimento

- alterações no ciclo de vida

- sobrevivência ou não numa determinada área

— redução da diversidade de espécies.

Dessa forma, os sintomas que as plantas apresentam, quando expostas a determinada concentração e tipo de poluente, podem servir como indicação do grau de contaminação ambiental. Biofiltros e bioacumuladores, no entanto, são organismos resistentes à poluição. Eles retratam o nível de contaminação atmosférica de forma semi-quantitativa, acumulando elementos ou ligas tóxicas via absorção e/ou adsorção (Guderian \& Schoenbeck 1971; Thomas 1983; Guderian 1986; Flores 1987). 
As plantas mais indicadas como biofiltro são os musgos e os liquens, por apresentarem as seguintes propriedades:

- ocorrência geográfica ampla

- resistência contra altas concentrações de poluição

- ausência de epiderme e cutícula, facilitando a entrada e o acúmulo de poluentes

- alta capacidade de troca catiônica

- retenção mecânica por apresentar uma grande superfície.

Segundo Clymo (1963); Ferguson et al. (1984). O mecanismo de acumulação de metais pesados, via deposição seca e úmida, pelo musgo Sphagnum procede principalmente das seguintes três formas:

— transporte para o interior das células aclorofiladas com auxílio de ácidos orgânicos formando complexos

- via troca iônica com as paredes celulares

- via retenção mecânica de partículas na superfície externa.

Obtem-se os dados sobre a acumulação de poluentes orgânicos e inorgânicos através da análise química das plantas expostas à poluição. A grande vantagem de bioacumuladores - que, por certo, não dispensam o emprego de coletores mecânicos convencionais - consiste no seu baixo custo de instalação e no seu manejo fácil permitindo um monitoramento de áreas extensas e de difícil acesso. Enquanto os coletores mecânicos registram valores momentâneos de determinados contaminantes, os biofiltros retratam uma situação global e real do meio biótico, revelando o impacto do conjunto complexo de emissões sobre a planta durante um certo tempo. A correlação com dados mesoclimáticos (direção e intensidade do vento, precipitação etc.) e topográficos (altitude, distância da fonte emissora etc.) específicos da área de estudo são indispensáveis na avaliação da poluição área.

\section{Objetivo}

Com a seguinte apresentação de primeiros dados referentes ao monitoramento de poluição atmosférica com saquinhos de musgo, experimentado pela primeira vez no Brasil na região Serra do Mar/Cubatão durante o ano de 1987, procurou-se:

1. demonstrar a alta capacidade do uso de Sphagnum no monitoramento semiquantitativo para metais pesados, confirmando a eficiência desse método

2. mostrar uma alternativa de menor custo para o monitoramento de contaminação aérea industrial

3. abrir a discussão no campo do biomonitoramento, com o objetivo de aperfeiçoar e estandardizar os métodos já existentes.

\section{Material e Métodos}

No presente trabalho o musgo Spagnum recurvum P. Beauv. foi utilizado como biofiltro em forma de "moss-bag". O experimento foi realizado durante o ano de 1987 na área da Serra do Mar de Cubatão- $\mathrm{SP}^{1}$. O método do moss-bag consiste na exposição de saquinhos de nylon contendo musgo em áreas industriais. Inicialmente foi descrito por Goodman et al. $(1974,1975)$ aperfeiçoado por Maekinen (1984); Hynninen (1986), e alterado para esta pesquisa adaptando o método às condições geográficas, físicas e econômicas presentes no Brasil.

1 Cubatão é um dos maiores aglomerados industriais no Brasil, contando com 23 indústrias no setor petroquímico, fertilizante e siderúrgico, altamente poluidoras. A produção industrial, numa localização geográfica extremamente desfavorável do ponto de vista da dispersão das emissões, assim como a filosofia econômica dominante utilizando-se o meio ambiente como "meio livre", sem preço, propiciou uma degradação ambiental muito séria. (Aspectos da degradação ambiental e das conseqüências ecológicas do caso Cubatão foram discutidos com maior profundidade em alguns capítulos da tese de doutoramento da autora, que será publicada no final de 1989). 
Uma quantidade certa de musgo, colocada em saquinhos de nylon, é exposta à poluição aérea em diversos locais por um tempo limitado. Periodicamente o musgo é trocado e analisado em laboratório, obtendo valores de acumulação de determinados elementos por período de exposição. No caso desta pesquisa foram escolhidos 24 pontos de amosiragem distribuídos na encosta da Serra do Mar e na área urbana e industrial de Cubatão, numa área total de aproximadamente $170 \mathrm{~km}^{2}$. Os pontos de amostragem cobrem a área tanto na vertical, com as diferentes altitudes, como na horizontal, pela distância do pólo industrial. Em cada ponto foram expostas quatro (4) amostras suspensas no suporte de madeira, projetado propriamente para este trabalho ${ }^{2}$ (Figura 1) e foram trocados mensalmente. O procedimento mensal no preparo do musgo sucedeu em duas fases:

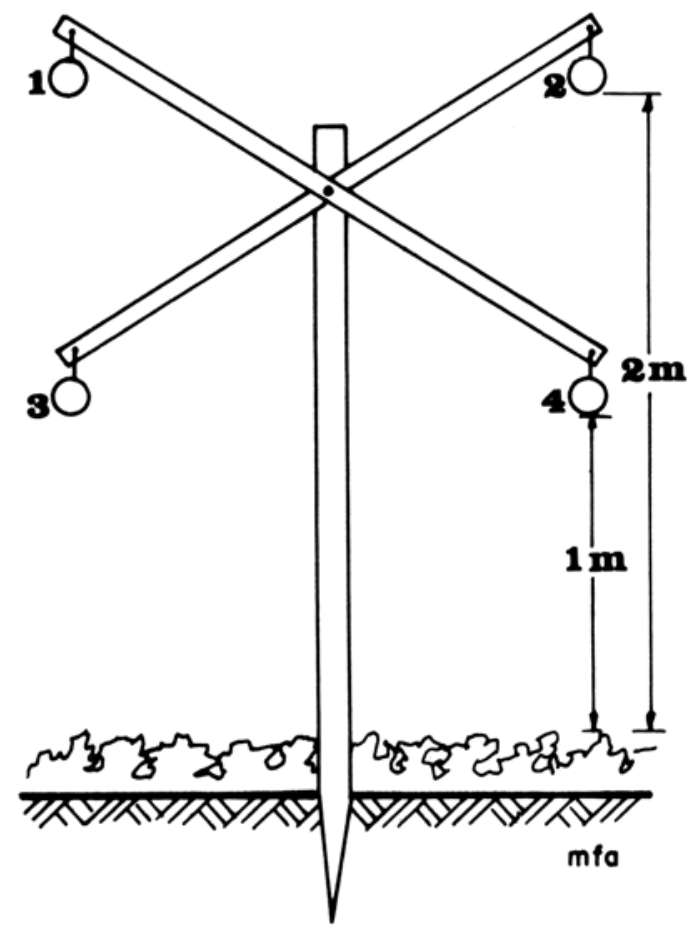

Figura 1 - Ponto de amostragem com quatro $(1,2,3,4)$ saquinhos de musgo.

\section{Primeira fase (antes da exposição):}

- coleta do Sphagnum numa região de baixa contaminação industrial (no caso foi escolhido uma área no litoral sul, $70 \mathrm{~km}$ de Cubatão)

- lavagem da planta com água e posteriormente com água destilada e deionizada

- pesagem da parte superior verde do musgo em saquinhos de nylon $(25 \mathrm{~g})$

- distribuição dos saquinhos nos pontos de amostragem no campo.

Segunda fase (após exposição)

- coleta do material exposto no campo

- secagem em estufa de circulação fechada $\left(60^{\circ} \mathrm{C}\right)$

2 De acordo com o método convencional, os saquinhos de musgo estão sendo presos em ramos de árvores. No entanto, esta forma não propricia condições de exposição homogêneas para todos os pontos e medição, além de não eliminar o fator da interceptação exercida pela copa das árvores. 
- pesagem do material seco

- moagem

- digestão ácida do material orgânico (seguinho em geral o método proposto pelo CENA (Centro de Energia Nuclear na Agricultura Piracicaba) (Bataglia et al. 1983) com adaptação específica ao material vegetal

- Análise por Espectrofotometria de Plasma, detectando as concentrações de metais pesados em ppm.

Para minimizar a contaminação do material, seguiu-se rigorosamente o método de uma forma homogênea para todos os pontos e períodos de amostragem. Mensalmente foram separadas dez (10) amostras de musgo, passando pelo mesmo tratamento de lavagem e secagem, porém não foram expostas à poluição de Cubatão. Estas amostras serviram de referência para conhecer a concentração básica dos elementos em estudo encontrados naturalmente na planta (valor controle).

\section{Resultados e Discussão}

Inicialmente o Sphagnum foi analisado para os seguintes elementos: Alumínio (A1), Ferro (Fe), Níquel (Ni) e Zinco (Zn). Os resultados da análise química foram representados na forma de acumulação relativa (\%/mês) e acumulação absoluta (ppm/peso se$\mathrm{co} / \mathrm{mês})$. $\mathrm{O}$ valor controle corresponde à média das concentrações dos respectivos metais, encontrados em dez (10) amostras que não foram expostas à poluição. Enquanto que o valor $\Delta$ (delta) representa o acúmulo do material exposto menos o valor controle em \%. As Figuras 2,3,4 e 5 retratam respectivamente a acumulação relativa e absoluta dos elementos $\mathrm{Fe}, \mathrm{Zn}, \mathrm{Al}$ e $\mathrm{Ni}$ no material exposto à poluição de Cubatão durante o mês de março de 1987. A grande discrepância entre o valor mínimo e o valor máximo ocorreu devido à grande entre o valor mínimo e o valor máximo ocorreu devido à heterogeneidade na distribuição geográfica dos 24 pontos de amostragem, variando desde pontos próximos à fonte poluidora até pontos menos expostos às emissões|industriais (Figuras $6,7)$. A acumulação foi significativa para todos os metais em questão, os elementos $\mathrm{Fe}$ e $\mathrm{Al}$, no entanto, representaram os maiores índices de retenção pelo musgo, provavelmente porque devem ser os metais emitidos mais freqüentemente e em maior concentração pelas indústrias de Cubatão. A acumulação elevada destes metais pode ser correlacionada com os seguintes fatores:

- a emissão de metais pesados provém principalmente da atividade siderúrgica e em menor quantidade dos processos da combustão presentes nos outros ramos de atividades industriais (fertilizantes, vários processos da refinação de petróleo, etc.)

- o musgo retém facilmente o ferro e o alumínio

A variação na acumulação de ferro e de alumínio durante o mês de março de acordo com os diferentes pontos de amostragem pode ser visto nas Figuras 6 e 7, respectivamente. Os valores em ppm/peso seco/mês correspondem à retenção absoluta. $\mathrm{O}$ musgos expostos somente a $1 \mathrm{~m}$ de altura do solo (amostras 3 e 4 ) apresentam em média maiores valores de acumulação para o mês de março e para os elementos em questão.

Este fato pode ser explicado pelas diferentes condições microclimáticas predominantes na altura de até 1 metro (intensidade do vento, temperatura geralmente mais elevada). $\mathrm{O}$ fato interferência de partículas do solo levantado pelo vento e pela erosão da chuva ("rain-splash-erosion"), no entanto, não deve influenciar na acumulação de uma forma dominante, porque os suportes para as bolsas de Sphagnum foram montados em locais distantes de qualquer rodovia e em solo coberto por gramíneas, evitando assim a formação de poeiras possivelmente levantadas do solo.

Os pontos de medição mais distantes das fontes emissoras como por ex. os números 4, 5, 6 e 7 e o ponto 18 localizado em frente à siderúrgica COSIPA (Companhia Siderúrgica Paulista) apresentam os valores máximos de acumulação (Figuras 6,7). Estes locais 
devem receber a maior concentração de poluentes porque estão localizados na direção principal dos ventos. A retenção de ferro no Sphagnum exposto próximo à refinaria Presidente Bernardes (n.s 11,12,13) foi praticamente insignificante. Também, para o alumínio o valor é baixo nesta localızação. Somente o ponto $\mathrm{n}^{\circ} 13$, a amostra maís próxima à instalação do pólo petroquímico, apresentou um resultado significativo. Porém, não devem ser os metais pesados as principais emissões deste ramo de atividade.

\section{Conclusões}

Devido ao elevado grau de degradação ambiental, principalmente nos grandes centros urbanos e industriais, a questão da determinação de poluentes atmosféricos tem alcançado uma importância mundial. Uma questão primordial, especialmente para as ciências ambientais, consiste na busca de métodos eficientes e de baixo custo para poder detectar, determinar e quantificar emissões industriais. Com este objetivo foi testado o método de bioacumulação "moss-bag", determinando a concentração de metais pesados atmosféricos numa área de estudo abrangendo a Serra do Mar e a área urbanoindustrial de Cubatão/SP/Brasil $\left(170 \mathrm{Km}^{2}\right)$. Foi elaborado um suporte de madeira para poder fixar em duas alturas os quatro saquinhos de Sphagnum, propiciando assim uma forma padronizada e homogênea para cada ponto de medição. Embora os resultados mostrados acima representem somente uma pequena parte da pesquisa em questão ${ }^{3}$ não deixam de confirmar o alto potencial científico da bioacumulação para o monitoramento de poluição atmosférica de metais pesados, além de contribuir com o aperfeiçoamento da forma de exposição do "moss-bag". A pesquisa evidenciou, ainda, o alto poder de acumulação de metais pesados pelo musgo Sphagnum, assinalando o seu uso como biofiltro em estudos ambientais. Várias questões relacionadas com o aprimoramento do método ainda estão em aberto, assim como:

- seletividade na absorção

— retenção de compostos orgânicos

- ponto de saturação

- diferente forma, quantidade e tempo de exposição.

\section{Reierências Bibliográficas}

BATAGLIA, O.C.; FURLANI, A.M.C.; TEIXEIRA, J.P.F.; FURLANI, P.R. \& GALLO, J.R. 1983. Métodos de análise química de plantas. Bol. Téen. Inst. Agron., Campinas, (78)

CLYMO, R.S.1963. Ion exchange in Sphagnum and its relation to bog ecology. Ann. Bot., 27:309-324.

FERGUSON, P.; ROBINSON, R.N.; PRESS, M.C. \& LEE, J.A.1984. Element concentrations in five Sphagnum species in relation to atmospheric pollution. J. Bryol., 13:107-114.

FLORES, F.E.V. 1987. O uso de plantas como bioindicadores de poluição no ambiente urbano - industrial: experiências em Porto Alegre, RS, Brasil. IN: KOHLHEPP, G. \& SCHRADER, A (Eds.). Okologische probleme in lateinamerika. "Tübinger Geographische studien. V.6, p. 79-86.

GOODMAN, G.T.; SMITH, S.; PARRY, G.D.R. \& INSKIP, M.J.1974. The use of mossbags as deposition gauges for airborne metals. Proc. Nat. Soc. for Clean Air., Cardiff.

3 Os resultados completos das concentrações dos metais; Al, Ba, Cd, Fem Ni, Mn e Zn, obtidos no monitoramento de janeiro a dezembro de 1987, nos 24 pontos de amostragem analisados estatisticamente (análise de regressão e de correlação, etc.), estão sendo apresentados na tese de doutoramento da autora que será publicada no final de 1989. 
GOODMAN, G.T., SMITH, S. \& INSKIP, M.J.1975. Moss bags as indicators of airborne metals - an evaluation. IN: REPORT of a collaborative study on certain elements in air, soil, plants, animals and human in the Swansea/ Neath/ Port Talbot area. p. 267-365.

GUDERIAN, R.1986. Kriterien zur Erfassung und Bewertung von Immissionsbelastungen in terrestrischen "Okosystemen. Verhandl. Gesell. Ökol., 14: 245-256.

GUDERIAN,R. \& SCHOENBECK, H. 1971. Recent results for recognition and monitoring of air pollutants with the aid of plants. IN: CONGR. INTERN. CLEAN AIR, New York. p. 266-273.

HYNNINEN, V. 1986. Monitoring of airborne metal pollution with moss bags near an industrial source at harjavalta, Southwest Finland. Ann. Bot. Fennici, 23:83-90.

MÄKINEN, A. 1984. Regional extent and relative proportion of different metal emissions in helsinki air studied by the moss bag technique. IN: Environm. Research oh the Nordic Ministerial Council NMC, Project MIL. Lillestrom.

THOMAS, W.1983. "Uber die Verwendung von pflanzen zur Analyse räumlicher spurensubstanz - immissionsmuster. IN: STAUB - REINHALT - LUFT Nº ${ }^{\circ}$ 3.p. 141-148. 


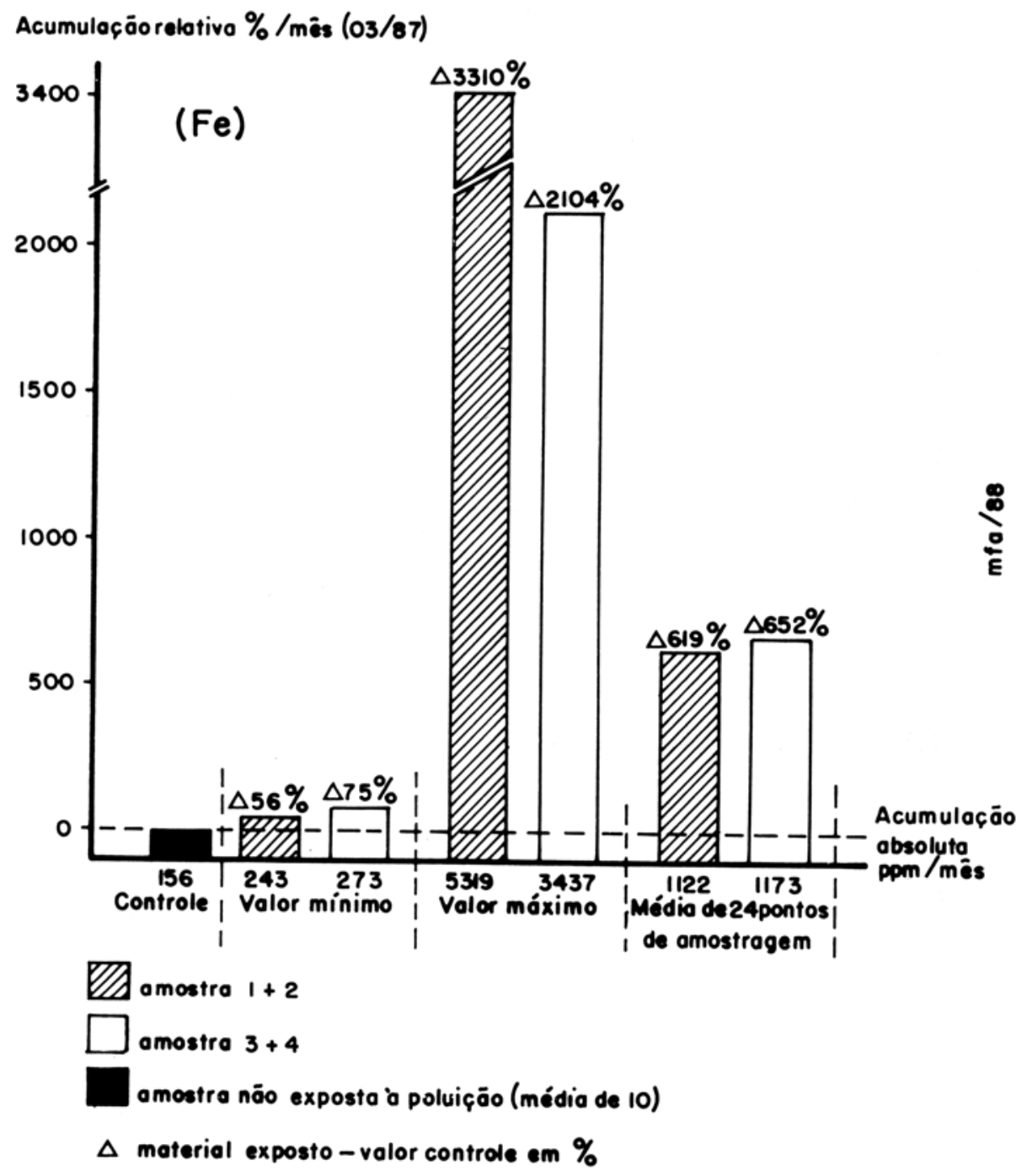

Figura 2 - Acumulação de Ferro ( $\mathrm{Fe}$ ) em saquinho de Sphagnum durante o mês 03/87 (em\%mês e ppm/peso seco/mês). 
Acmulaçäo relativo $\% / \mathrm{mês}(03 / 87)$

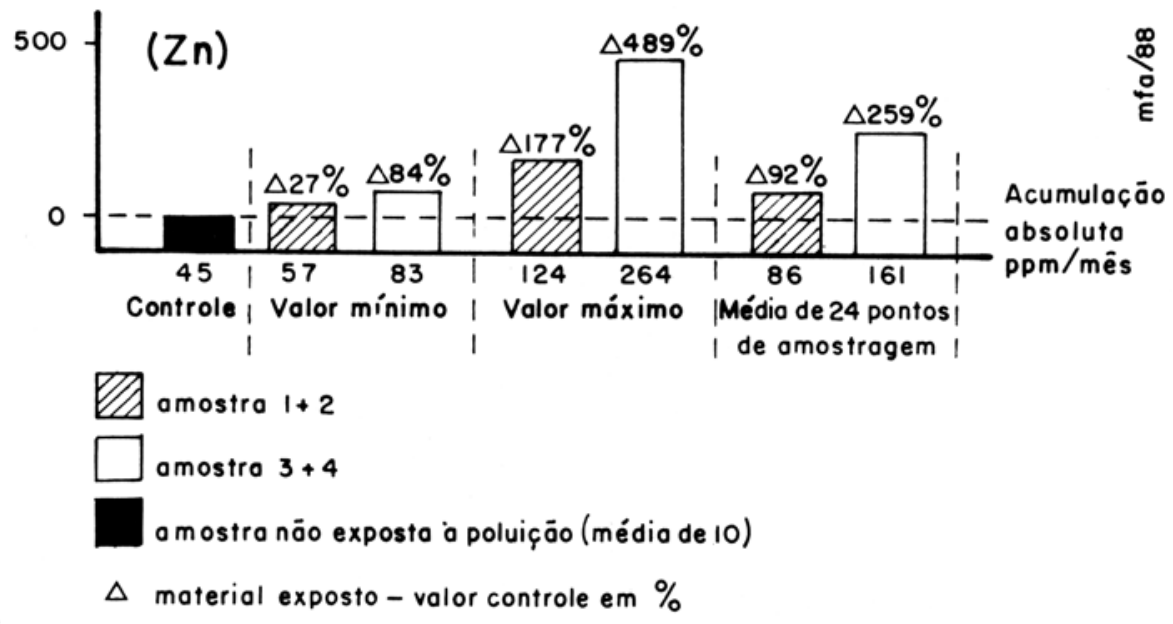

Figura 3 - Acumulação de Zinco (Zn) em saquinho de Sphagnum durante o mês 03/87 (em \%/mês e ppm/peso eco/mês). 
Acumulaçäo relativo $\% /$ mês $(03 / 87)$

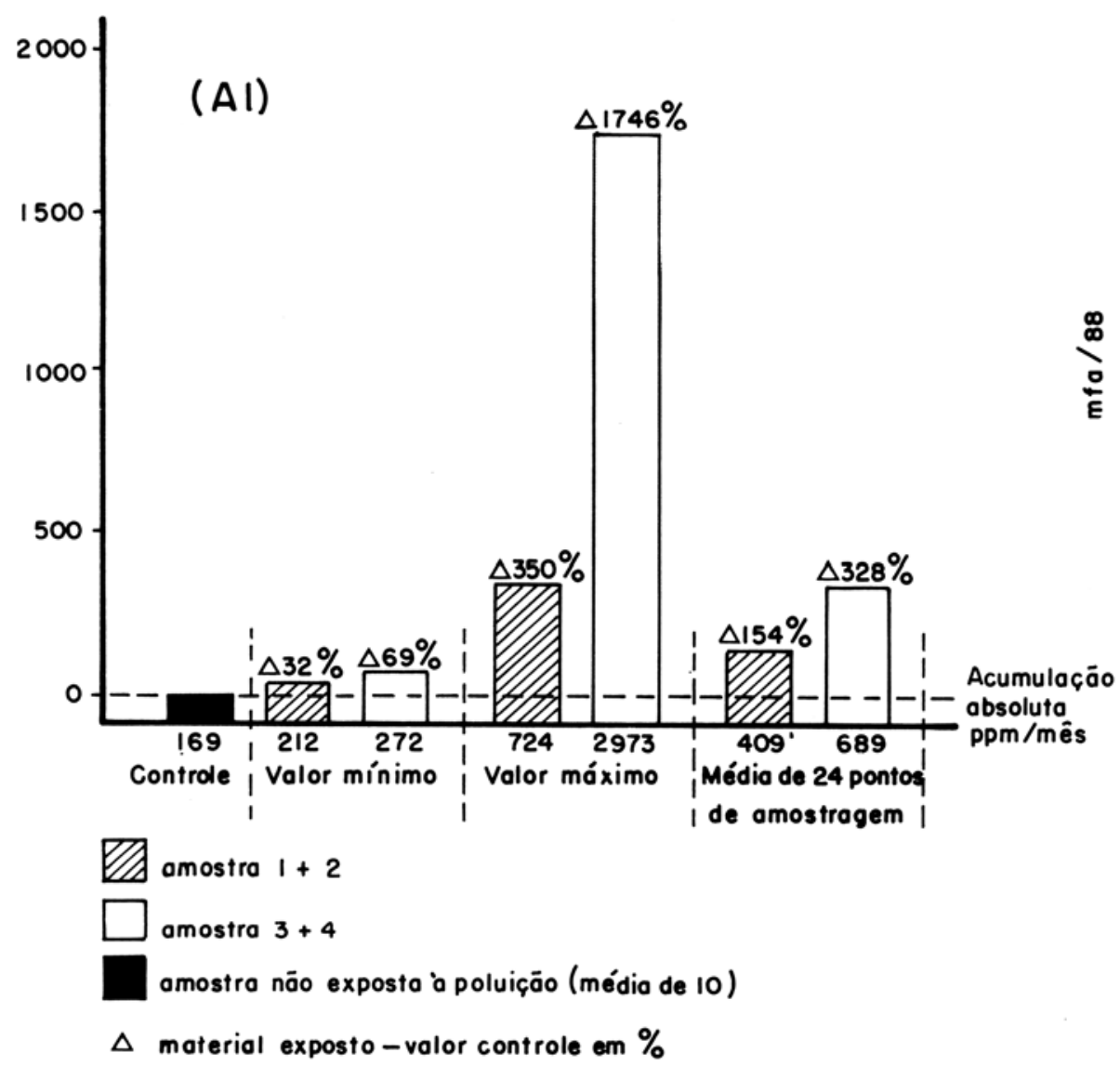

Figura 4 - Acumulação de Alumínio (Al) em saquinho de Sphagnum durante o mês 03/87 (em \%/mês e ppm/peso seco/mês). 
Acumulaçäo relativa \% / môs (03/87)

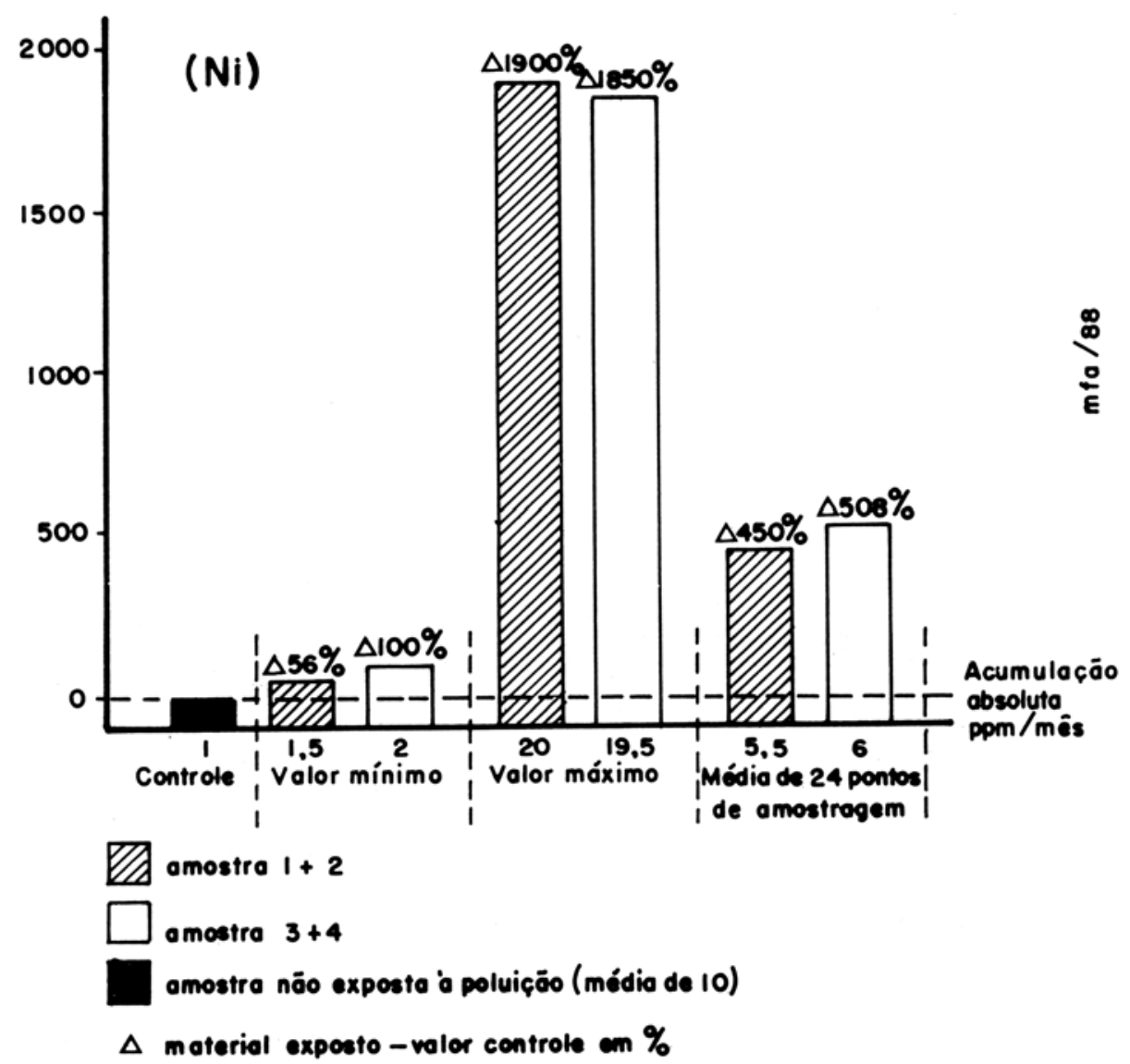

Figura 5 - Acumulação de Níquel (Ni) em saquinho de Sphagnum durante o mês 03/87 (em \%/mês e ppm/peso seco/mês). 
Concentraçäo ppm/mês (03/87)

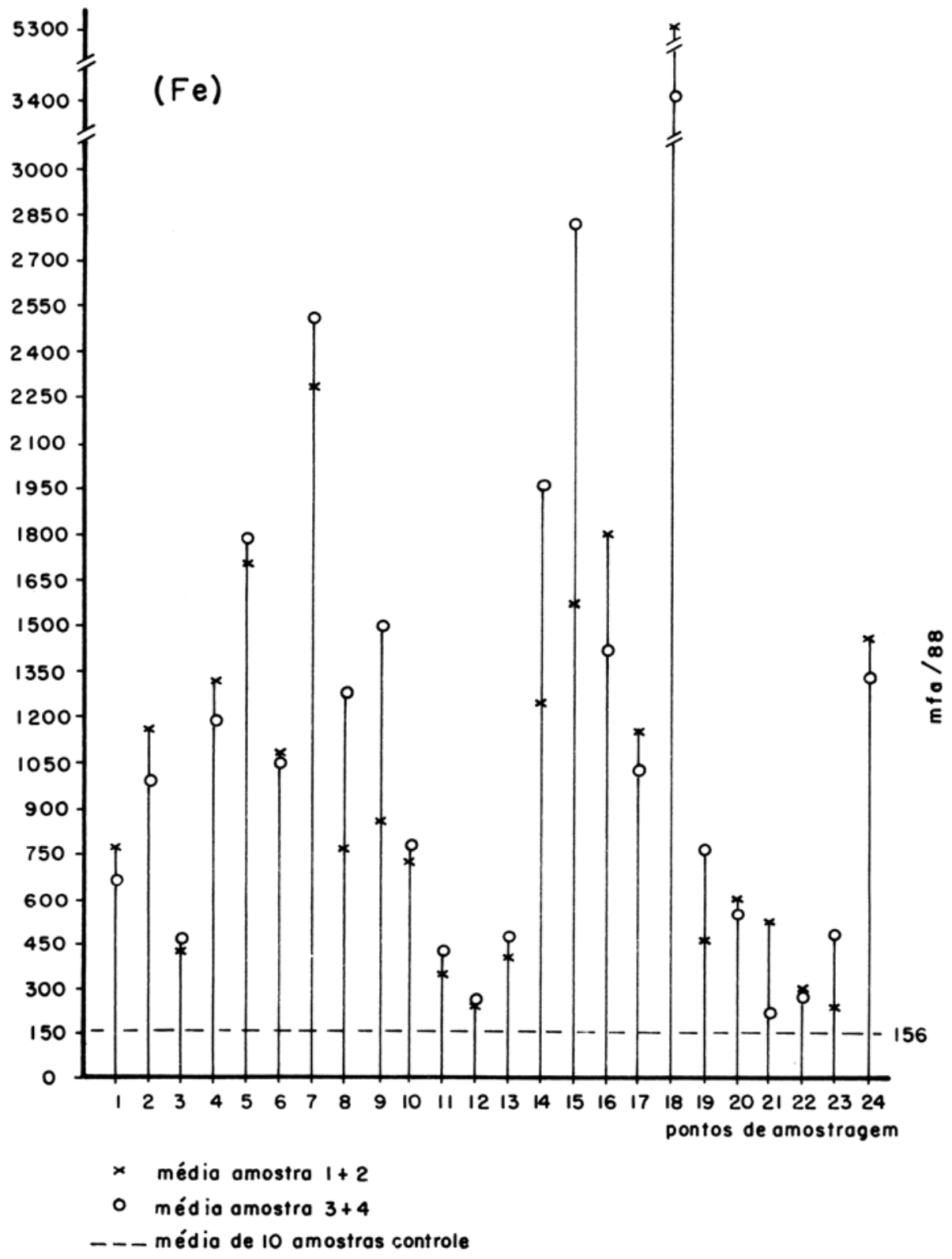

Figura 6 - Acumulação de Ferro (Fe) em saquinho de Sphagnum durante o mês 03/87 e 24 pontos de amostragem (ppm/peso seco/mês). 
Concentroçäo ppm /mâs (03/87)

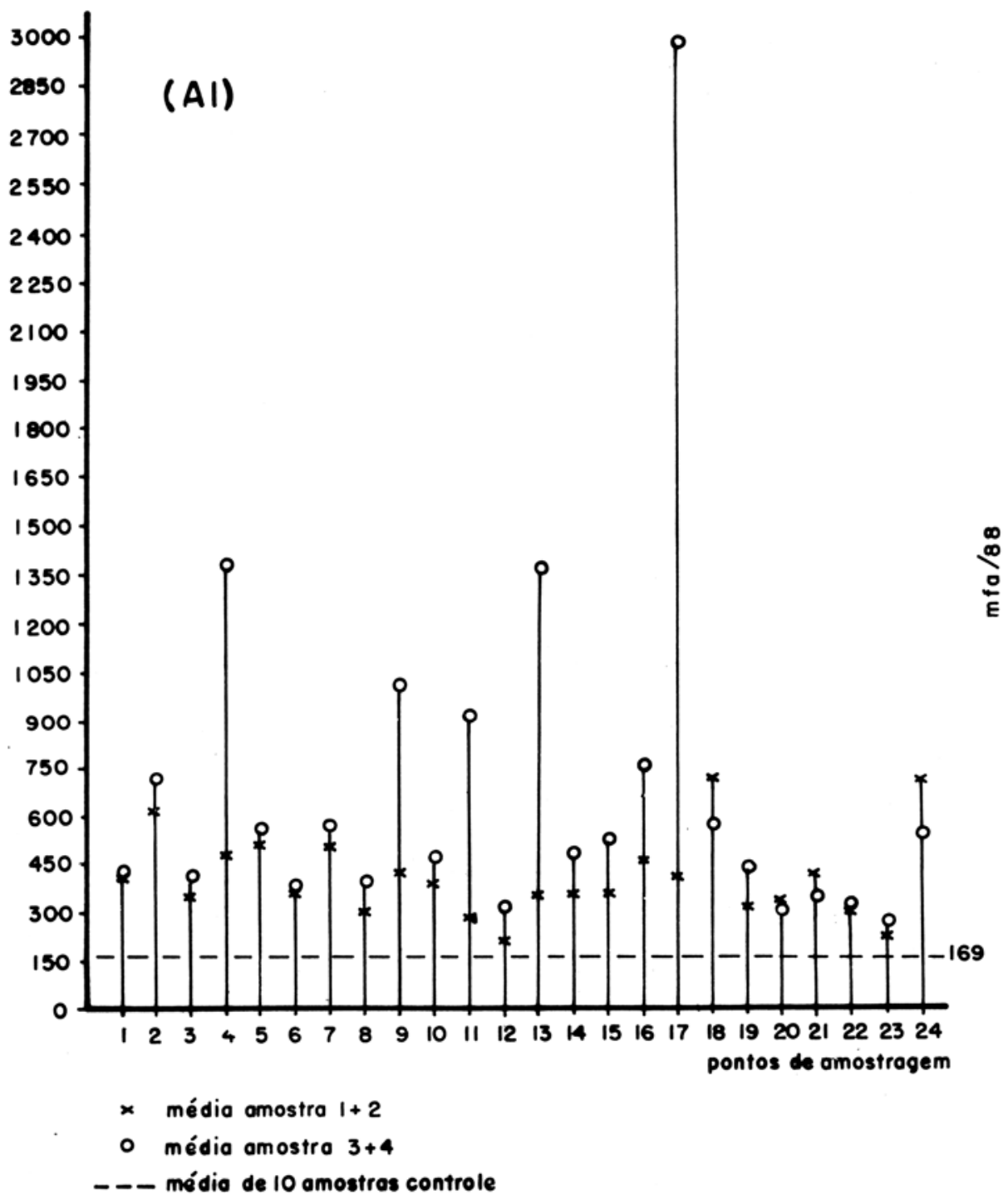

Figura 7 - Acumulą̧ão de Alumínio (Al) em saquinho de Sphagumm durante o mês 03/87 em 24 pontos de amostragem (ppm/peso seco/mês). 